\title{
Retail input-output Analysis Based on DEA Method
}

\author{
Xu Ronghui \\ Wu Han University of Technology, Wu Han, China
}

Keywords: Listed retail; input and output efficiency; deal; BCC.

Abstract. Along with our country economy into the new normal, retailing development bottlenecks encountered unprecedented, but the development of the retail industry of our country play a crucial role in the development of national economy, and is also about the life of the national level, so it is very important to study retailing. And throughout the problem of the retail industry is the most major problem raises costs and profits decline, it is associated with the input and output efficiency of retail. BCC model of this article is based on DEA and index method to analyze the efficiency of China's listed retail, specific for entity retail enterprise in 2007-2016 the input and output efficiency of the comparative analysis.

\section{Introduction}

Retail enterprises have a history of more than 160 years since the beginning of the reform and opening up. However, in recent years, real retail enterprises have presented a series of problems, input-output efficiency. There is a bottleneck state, many entity retail enterprises blindly expand the size and operating efficiency of a sustained decline stage, resulting in the cost of rising and profit reduction. As a retail enterprise, how to improve its input-output ratio, it must be in the development process of its input-output quantitative analysis.

\section{Literature Review}

Taking the internal retail stores of chain enterprises as an example, Thomas and so on analyzed a cross-regional retail enterprise in 1998. The enterprise has 522 branches, mainly using data envelopment analysis (DEA), to a certain extent reflects the existing problems of American retail enterprises, and gave the corresponding guidance measures for the United States zero. ${ }^{[1]}$ The development of sales industry laid the foundation. Taking the comparative analysis of the efficiency of online and offline retail enterprises as an example, Zhao Mengjia used DEA to analyze 10 listed retail enterprises, 4 online listed retail enterprises and 2 online retail unlisted enterprises in his "Research on the Input-Output Efficiency Evaluation of Online and Offline Retail Enterprises in 2014". It shows that we should improve the construction of commercial infrastructure. ${ }^{[2]}$

\section{Research Design}

\subsection{Selection of DEA data}

The main purpose of this paper is to measure the input-output efficiency of the retail industry of listed companies. It is mainly used in BCC model to measure the input-output efficiency of listed companies. The software used for data analysis in this paper is DEAP2.1. The input-output efficiency of the retail industry of listed companies is calculated and the input-oriented model is selected.

R. D. Banker, A. Charnes and W. W. Cooper proposed the BCC model in 1984. They revised the basic assumptions in the CCR model, because the model would evaluate whether the decision-making unit has reached an effective production scale, so the scale efficiency and technical efficiency can be measured simultaneously. ${ }^{[3]}$

\subsection{The main DEA model}

There are two commonly used DEA methods: constant return on scale (CRS) and variable return on scale (VRS). CCR model and BCC model are used to calculate their respective efficiency values. The mathematical expression is as follows: if there are $\mathrm{N}$ retail enterprises, each of them has $\mathrm{M}$ input $x_{j}=$ $\left(x_{1 j}, x_{2 j}, \cdots, x_{m j}\right)^{T}$, S output $y_{j}=\left(y_{1 j}, y_{2 j}, \cdots, y_{m j}\right)^{T}$ mode, $\lambda_{j}$ is the weight coefficient of the input 
and output index, $S^{+}, S^{-}$is the relaxation variable, and $\varepsilon$ is a non-Archimedean infinitesimal quantity.In the case of fixed scale returns, the CCR model can be expressed as:

$$
\left\{\begin{array}{c}
\min =\theta-\varepsilon\left(\hat{e}^{\mathrm{T}} S^{-}+\mathrm{e}^{\mathrm{T}} S^{+}\right) \\
\text {s.t. } \sum_{j=1}^{n} x_{j} \lambda_{j}+S^{-}=\theta x_{0} \\
\sum_{j=1}^{n} y_{j} \lambda_{j}-S^{+}=\theta y_{0} \\
\lambda_{j} \geq 0, S^{-} \geq 0, S^{+} \geq 0 \\
\hat{e}=(1,1, \cdots, 1)^{T} \in R^{m} \\
\mathrm{e}=(1,1, \cdots, 1)^{T} \in R^{s}
\end{array}\right.
$$

Among them, if the $\theta=1, S^{-}=S^{+}=0$, that is DMU effective, then the production efficiency is in the optimal state; if the $\theta=1$, and $S^{-} \neq 0, S^{+} \neq 0$, that is weak DMU effective; if the $\theta<1$, that is, DMU ineffective. $^{[4]}$

\subsection{Input oriented BCC model}

DEA validity under CCR model refers to the combination of pure technology validity and scale validity, that is, technology validity. However, the effectiveness of DEA under the BCC model only refers to simple technical efficiency, that is, pure technology is effective. There is a certain relationship between comprehensive efficiency (i.e. technical efficiency), pure technical efficiency and scale efficiency, i.e. comprehensive efficiency divided by scale efficiency results is pure technical efficiency. The BCC mathematical model of variable scale returns is:

$$
\left\{\begin{array}{c}
\min =\theta-\varepsilon\left(\hat{e}^{T} S^{-}+e^{T} S^{+}\right) \\
\text {s.t. } \sum_{j=1}^{n} x_{j} \lambda_{j}+S^{-}=\theta x_{0} \\
\sum_{j=1}^{n} \lambda_{j}=1, \lambda_{j} \geq 0 \\
S^{-} \geq 0, S^{+} \geq 0 \\
\hat{e}=(1,1, \cdots, 1)^{T} \in R^{m} \\
e=(1,1, \cdots, 1)^{T} \in R^{s}
\end{array}\right.
$$

Note: $\theta$ is no positive or negative restrictions. ${ }^{[5]}$

\section{Empirical Research}

\subsection{Selection and establishment of evaluation index system}

At present, many domestic scholars have studied the input-output efficiency of retail industry by using DEA method. In order to evaluate the input-output efficiency of Listed Retail Enterprises better, the paper chooses three input indicators: the number of employees, the net fixed assets and the current assets. The two output indicators are: main business profit and main business income. The index is defined in table as follows:

Table 1 The index of this article

\begin{tabular}{|c|l|}
\hline First level index & Second level index \\
\hline \multirow{3}{*}{ Input indicator } & R: number of employees (people) \\
\cline { 2 - 2 } & F: net assets of fixed assets (10000 Yuan) \\
\cline { 2 - 2 } & C: liquid assets (10000 Yuan) \\
\hline \multirow{2}{*}{ Output index } & I: main business income (10000 Yuan) \\
\cline { 2 - 2 } & P: main business profit (10000 Yuan) \\
\hline
\end{tabular}




\subsection{Efficiency evaluation of DEA method}

Using the software DEAP2.1, 15 listed retail companies in China are taken as decision-making units to analyze the input and output data (see appendix for the original data). The comprehensive efficiency, the pure technical efficiency and the scale efficiency are respectively analyzed as follows:

Table 2 Comprehensive efficiency analysis results

\begin{tabular}{|c|c|c|c|c|c|c|c|c|c|c|c|}
\hline $\mathrm{C}$ & 2007 & 2008 & 2009 & 2010 & 2011 & 2012 & 2013 & 2014 & 2015 & 2016 & mean value \\
\hline 1 & 1.00 & 0.51 & 0.84 & 1.00 & 1.00 & 1.00 & 1.00 & 1.00 & 1.00 & 1.00 & 0.93 \\
\hline 2 & 0.68 & 0.51 & 0.73 & 0.77 & 0.96 & 0.79 & 0.79 & 0.82 & 0.73 & 0.70 & 0.75 \\
\hline 3 & 1.00 & 0.41 & 0.57 & 1.00 & 0.92 & 1.00 & 1.00 & 1.00 & 0.96 & 1.00 & 0.89 \\
\hline 4 & 1.00 & 1.00 & 1.00 & 1.00 & 0.83 & 0.84 & 0.93 & 0.97 & 0.94 & 0.95 & 0.95 \\
\hline 5 & 0.79 & 0.72 & 0.75 & 0.76 & 1.00 & 1.00 & 1.00 & 1.00 & 1.00 & 1.00 & 0.90 \\
\hline 6 & 0.63 & 0.22 & 0.53 & 0.46 & 0.45 & 0.88 & 0.55 & 0.68 & 0.52 & 0.56 & 0.55 \\
\hline 7 & 0.45 & 0.15 & 0.12 & 0.32 & 0.18 & 0.19 & 0.41 & 0.49 & 0.45 & 0.61 & 0.34 \\
\hline 8 & 0.66 & 0.40 & 0.33 & 0.31 & 0.52 & 0.42 & 1.00 & 1.00 & 1.00 & 1.00 & 0.67 \\
\hline 9 & 0.81 & 0.46 & 0.58 & 0.98 & 0.69 & 0.67 & 0.89 & 1.00 & 1.00 & 1.00 & 0.81 \\
\hline 10 & 1.00 & 1.00 & 0.96 & 0.94 & 1.00 & 1.00 & 1.00 & 1.00 & 1.00 & 1.00 & 0.99 \\
\hline 11 & 1.00 & 1.00 & 1.00 & 1.00 & 1.00 & 1.00 & 1.00 & 1.00 & 1.00 & 1.00 & 1.00 \\
\hline 12 & 0.24 & 0.28 & 0.28 & 0.24 & 0.35 & 0.37 & 0.38 & 0.82 & 1.00 & 0.93 & 0.49 \\
\hline 13 & 0.94 & 0.74 & 1.00 & 0.86 & 0.90 & 0.98 & 0.90 & 1.00 & 1.00 & 0.94 & 0.93 \\
\hline 14 & 0.74 & 0.67 & 0.84 & 0.75 & 1.00 & 1.00 & 1.00 & 0.80 & 1.00 & 0.97 & 0.88 \\
\hline 15 & 0.83 & 0.77 & 0.93 & 0.75 & 0.93 & 1.00 & 1.00 & 1.00 & 1.00 & 0.86 & 0.91 \\
\hline
\end{tabular}

Table 3 Target value improved after non DEA effective unit

\begin{tabular}{|c|l|l|l|l|l|}
\hline $\begin{array}{c}\text { Serial } \\
\text { number }\end{array}$ & \multicolumn{1}{|c|}{$\begin{array}{c}\text { Number of } \\
\text { workers }\end{array}$} & \multicolumn{1}{|c|}{$\begin{array}{c}\text { Net fixed } \\
\text { assets }\end{array}$} & \multicolumn{1}{|c|}{$\begin{array}{c}\text { current } \\
\text { assets }\end{array}$} & \multicolumn{1}{|c|}{$\begin{array}{c}\text { Main business } \\
\text { income }\end{array}$} & \multicolumn{1}{|c|}{$\begin{array}{c}\text { Main business } \\
\text { profit }\end{array}$} \\
\hline 1 & 12563.000 & 35073.000 & 206474.000 & 670955.000 & 3918.000 \\
\hline 2 & 7980.000 & 139383.000 & 509660.000 & 1305575.913 & 64082.356 \\
\hline 3 & 70440.000 & 310869.000 & 2056633.000 & 4923165.000 & 149760.000 \\
\hline 4 & 10501.000 & 273331.000 & 1018539.000 & 1779512.000 & 78858.000 \\
\hline 5 & 6046.000 & 79497.000 & 479464.000 & 1007740.000 & 54818.000 \\
\hline 6 & 8897.000 & 194855.894 & 832990.226 & 1374788.834 & 116981.567 \\
\hline 7 & 3669.000 & 42133.000 & 736098.000 & 304147.000 & 20452.000 \\
\hline 8 & 15388.000 & 290407.000 & 1875313.000 & 1699959.000 & 407242.000 \\
\hline 9 & 20292.000 & 68766.000 & 748173.000 & 1235821.000 & 1896.000 \\
\hline 10 & 22026.000 & 245342.000 & 762163.000 & 3384677.000 & 49204.000 \\
\hline 11 & 4867.000 & 90552.000 & 244901.000 & 906967.000 & 26832.000 \\
\hline 12 & 3679.000 & 123368.906 & 280675.751 & 559321.030 & 45177.670 \\
\hline 13 & 10261.679 & 171384.089 & 366425.000 & 1580680.864 & 22301.091 \\
\hline 14 & 12876.000 & 226933.000 & 430579.000 & 549480.000 & 84320.000 \\
\hline 15 & 1393.000 & 115630.000 & 68093.000 & 220716.000 & 2020.000 \\
\hline
\end{tabular}

As can be seen from the above table, productivity can be improved by improving the quality of employees and reducing redundancy; unreasonable components of liquid assets can be reduced by reducing the backlog of inventory and handling accounts receivable; and we should reduce procurement costs and operational success by integrating effective resources to improve profitability. Ben. Then we can expand our scale to achieve scale effect. Perfect logistics and distribution technology and the use of information technology can help retail enterprises to solve the shortage and inventory paradox.

\section{Conclusions}

Through the improvement of non-DEA effective retail enterprises, it is found that the whole retail industry has redundant investment in fixed assets and mobile assets, while in output, although the overall 
retail revenue output efficiency is better, the overall profit output efficiency is still not high and needs to be improved.

The influence of technology began to become the dominant factor, and the influence of scale began to weaken.

\section{Acknowledgment}

The study supported by “the National Social Science Foundation Project (17BG209), Hubei Science and Technology Department Soft Science Research Project (2018ADC020), Central University Funds for Basic Scientific Research (2018VI001)”.

\section{References}

[1]. Fu Jing, Sun Binbin. Efficiency evaluation based on DEA retail chain industry [J]. Economic Research Guide.2007 (6). (In Chinese)

[2]. Lei Bing, Zhao Mengjia. Evaluation of input-output efficiency of online and offline retail enterprises [J]. Statistics and Information Forum. 2015. (5). (In Chinese)

[3]. Charnes, A, Cooper, W.W. and Rhodes, E.. Measuring the Efficiency of Decision Making Units [J]. European Journal of Operational Research. 1978, 2(6):429-444.

[4]. Farrell. M. J.. The Measurement of Productive Efficiency [J]. Journal of the Royal Statistical Society. 1957, 120(3):253-281.

[5]. Caves, D. W., Christensen, L R and Diewert, W. E.. The Economic Theory of Index Numbers and the Measurement of Inputs, Outputs and Productivity[J]. Econometrica. 1982, 50(6):1393-1414. 